Topics in Plant Population Biology 


\title{
TOPICS \\ IN \\ PLANT \\ POPULATION BIOLOGY
}

\author{
edited by \\ OTTO T. SOLBRIG \\ SUBODH JAIN \\ GEORGE B. JOHNSON \\ PETER H. RAVEN
}


(C) Columbia University Press 1979

Softcover reprint of the hardcover 1st edition 1979 978-0-333-26414-0

All rights reserved. No part of this publication may be reproduced or transmitted, in any form or by any means, without permission.

First published 1979 by THE MACMILLAN PRESS LTD

London and Basingstoke Associated companies in Delhi Dublin Hong Kong Johannesburg Lagos Melbourne New York Singapore and Tokyo 


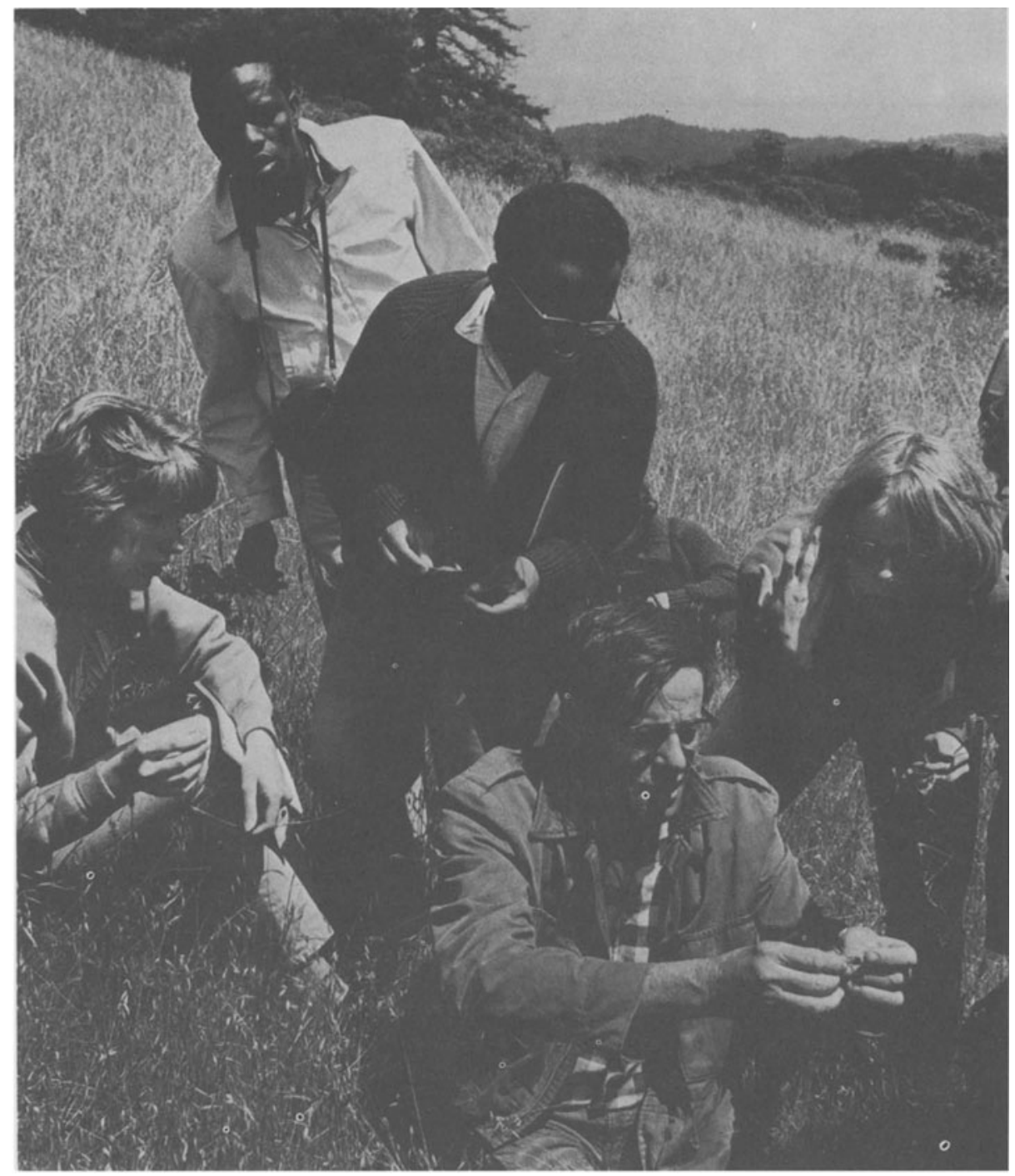

To George Ledyard Stebbins

Scientist, Teacher, Friend 


\section{CONTENTS}

List of Contributors

ix

Introduction $\quad x i$

George Ledyard Stebbins. отто T. SOLBRIG 1

1. Fifty Years of Plant Evolution. G. LEDYARD STEBBINS

Part 1. Adaptation and Genetic Variation in Populations

Introduction

2. Adaptation from the Perspective of

Optimality. HENRY S. HORN

48

3. Enzyme Polymorphism: Genetic Variation in the Physiological Phenotype. GEORGE B. JOHNSON

4. Genetic Variation and Longevity. J. L. HAMRICK 84

5. A Cost-Benefit Analysis of Recombination in Plants. OTTO T. SOLBRIG

6. Pollinator Foraging Behavior: Genetic Implications for Plants. DONALD A. LEVIN

Part 2. Life-Cycle Parameters

Introduction

7. Adaptive Strategies: Polymorphism, Plasticity, and Homeostasis. SUBODH JAIN

8. Seed Germination Syndromes in Higher

Plants. MARK W. ANGEVINE and BRIAN F.

CHABOT

9. Patterns of Juvenile Mortality and Recruitment in

Plants. ROBERT EDWARD COOK 
10. The Basic Biology of Plant Numbers. JAMEs C. HICKMAN

11. The Origin of Phenotype in a Recently Evolved Species. L. D. GOTTLIEB

12. Competition and Coexistence of Similar Species. PATRICIA A. WERNER

Part 3. Energy Harvest and Nutrient Capture Introduction

13. Environmental and Evolutionary Constraints on the Photosynthetic Characteristics of Higher Plants. H. A. MOONEY and S. L. GULMON

14. Drought-Stress Effects on Leaf Carbon Balance. BRIAN F. CHABOT AND JAMES A. BUNCE

15. The Climatology of the $\mathrm{C}_{4}$ Photosynthetic Pathway. J. A. TEERI

16. On the Adaptive Significance of Leaf Form. THOMAS GIVINISH

17. Root Structure: The Considerable Cost of Belowground Function. MARTYN M. CALDWELL 408

18. Canopy Structure and Environmental Interactions. P. C. MILLER and W. A. STONER

\section{Part 4. Summary and Conclusions}

19. Future Directions in Plant Population

Biology. PETER H. RAVEN

Literature Cited 483

Participants in the Ithaca Conference 575

Taxon Index 579

Subject Index 


\section{LIST OF CONTRIBUTORS}

Mark W. Angevine. Section of Ecology and Systematics, Cornell University, Ithaca, N.Y. 14850.

James A. Bunce. Light and Plant Growth Laboratory, U.S. Dept. of Agriculture, Beltsville, Md. 20705.

Martyn M. Caldwell. Department of Range Science, Utah State University, Logan, Utah 84322.

Brian F. Chabot. Section of Ecology and Systematics, Cornell University, Ithaca, N.Y. 14850.

Robert E. Cook. Department of Biology, Harvard University, Cambridge, Mass. 02138.

Thomas Givnish. Department of Biology, Harvard University, Cambridge, Mass. 02138.

Leslie D. Gottlieb. Department of Genetics, University of California, Davis, Calif. 95616.

Sherry L. Gulmon. Department of Biology, Stanford University, Stanford, Calif. 94305.

James L. Hamrick. Department of Botany, University of Kansas, Lawrence, Kan. 66044.

James C. Hickman. Department of Biology, Swarthmore College, Swarthmore, Pa. 19081 (present address: Dept. of Botany, University of California, Berkeley, Calif. 94720).

Henry S. Horn. Department of Biology, Princeton University, Princeton, N.J. 08540.

Subodh Jain. Department of Agronomy, University of California, Davis, Calif. 95616.

George B. Johnson. Department of Biology, Washington University, St. Louis, Mo. 63130.

Donald L. Levin. Department of Botany, University of Texas, Austin, Tex. 78712.

Phillip C. Miller. Systems Ecology Group, San Diego State University, San Diego, Calif. 92182. 
Harold A. Mooney. Department of Biology, Stanford University, Stanford, Calif. 94305.

Peter H. Raven. Missouri Botanical Garden, St. Louis, Mo. 63110.

Otto T. Solbrig. Department of Biology, Harvard University, Cambridge, Mass. 02138.

G. Ledyard Stebbins. Department of Genetics, University of California, Davis, Calif. 95616.

William A. Stoner. Systems Ecology Research Group, San Diego State University, San Diego, Calif. 92182.

James A. Teeri. Barnes Laboratory, The University of Chicago, Chicago, Ill. 60637.

Patricia A. Werner. W. K. Kellogg Biological Station, Michigan State University, Hickory Corners, Mich. 49060. 


\section{INTRODUCTION}

POPULATION BIOLOGY is concerned with the documentation and explanation of changes in gene frequency, number of individuals, and phenotypic characteristics of members of populations over time. Population biology includes aspects of population genetics, demography, population ecology, plant physiology, and adaptive morphology; it is primarily a synthetic discipline.

The two main objectives of population biology are: to understand in precise detail how natural selection operates (this involves not only determining that heritable changes take place but establishing precisely when and where in the life cycle these changes occur) and to understand rigorously the mechanisms of adaptation. It is not sufficient, therefore, to establish a correlation between the presence of a given phenotypic characteristic and a set of environmental factors, but it is necessary to provide the causal factors. Consequently, the population biologist tries to establish the patterns of genetic and phenotypic variation in time and space, hoping to understand how these patterns arise by the action of natural selection and in exactly what ways they are adaptive, in order to develop predictive models and theories.

Biological phenomena are, however, so complex, so multidimensional, that they cannot be understood by the patient accumulation of data, no matter how accurately and carefully gathered. Theoretical notions are necessary in the quest for knowledge, notions that often are deemed "tautological, Panglossian, teleological speculations" (discussed further by Horn, article 2 in this volume). Since counterexamples to any theory can usually be found, biological theories are not necessarily disproven by the performance of a single crucial experiment as in the physical sciences (where this model of proof may also be invalid in a large number of cases; Kuhn, 1970) but 
stand or fall in direct measure to their general predictive power. Good theories are those that lead to new insights, or new twists, and thereby help in the gathering of new and appropriate data.

Plant population biology is no different in its objectives than animal population biology (Harper, 1977). However, because plants as organisms have special characteristics, the investigation of the population biology of plants has certain unique advantages and disadvantages that require special approaches and techniques.

The most obvious characteristic of plants, which applies to all land plants and a large number of aquatic plants, is their sessile nature. This is shared by a small number of marine animals, most notably corals. The sessile nature of plants makes them very good material for demographic studies. Although the individual plantthe ramet-is truly sessile, the genotype-the genet-has a certain degree of mobility, which appears in the form of runners, stolons, or other forms of asexual reproduction, that allows an individual to produce exact genetic replicates. Although occasionally this form of movement is appreciable-as in the case of the aspen (Populus tremuloides), where an individual genotype is capable of occupying an entire hillside of several acres-vegetative reproduction, although complicating demographic studies, is not an overwhelming problem.

Interactions between sessile plants, both intra- and inter-specific, as well as interactions with the physical environment, are largely individual and very localized processes. Each plant has a unique physical environment, a unique set of competitors, and a unique set of herbivores and parasites, from which there is no escape. Therefore, by necessity, any models in plant population must include a vector indicating this neighborhood effect (Mack and Harper, 1977). As Schaffer and Leigh (1976) have pointed out, however, spatial relations are very difficult to model and to measure.

Another advantage of plants over animals in population biology studies is the relative ease of handling live plants and the facility with which they are reproduced vegetatively. This allows the design of replicate experiments with identical genetic individuals, without the necessity of inbreeding or special genetic manipulations. On the other hand, plants as a group have long generations, and it is seldom 
possible to obtain more than one or two generations a year; plants also tend to be bulkier, requiring more space, and for a longer time, than experiments with Drosophila, or even mice.

Plant species show a great degree of variation in life-cycle characteristics, longevity, breeding systems, and physiological and morphological traits. This facilitates observations and experiments on adaptation. Plants, however, are phenotypically very plastic, which makes studies of adaptation, and especially of selection, quite difficult. The plasticity of the phenotype almost mandates a determination of the genetic and environmental components of the variance in studies of plant populations, a time-consuming procedure that is very seldom followed.

Finally, plants are simply built, and their development and function should be easier to comprehend than those of most animals, particularly vertebrates, with their complex nervous and endocrine systems. On the other hand, plants have a very complex chemistry owing to the presence of a very large number of so-called secondary compounds (flavonoids, tannins, complex carbohydrates, etc.). The presence of these compounds not only makes the study of intermediate metabolism in plants very difficult, it makes the application of one of the most powerful techniques of modern population genetics-determination of allozyme phenotypes-very difficult.

Plants, therefore, present advantages and disadvantages compared to animals for population biology studies. However, it is the unique role of green plants as harvesters of solar energy that makes their study imperative as well as fascinating.

The last 20 years have seen the development of many novel and powerful concepts and techniques that have propelled population biology forward at an accelerating pace. In the realm of genetics, the introduction of allozyme techniques by Harris (1966) and Hubby and Lewontin (1966) has provided a powerful tool to ascertain gerie and genotype frequencies in populations and their change over time. Developmental genetics, that is, efforts to map genotypes into phenotypes, has made slower progress. The present inability to predict phenotypic composition from genotypic structure of a population, and vice versa, is probably the largest lacuna in our understanding of populations. Development of a more rigorous theoretical analysis 
of the components of natural selection, owing mostly to Prout (1969), and the introduction of notions of optimality into evolutionary theory (Rosen, 1967) have materially aided in increasing the level of rigor with which problems of selection and adaptation are attacked today. A more detailed discussion is found in Part 1 of this book.

Largely owing to the activities of John Harper, Anthony Bradshaw, and their students, plant population biologists have become very aware of the importance of understanding the meaning of the various aspects of the life cycle of plants. The concept is of course not new: Schimper (1898), in his classical treatise, attempted to explain the characteristics of the various ontogenetic stages of a plant in ecological and adaptive terms. However, demographic approaches in plant evolution and plant ecology have not been exploited until recently. As is pointed out by several contributors to this volume (Cook, article 9; Hickman, article 10; Werner, article 12), it is becoming increasingly clear that plant evolution is influenced enormously by the fate of seeds and seedlings. Traditionally, these stages have been neglected by taxonomists as well as ecologists. We need studies that record genetic and demographic changes simultaneously during these early stages of the life cycle.

Another interesting area is life-history theory (Gadgil and Bossert, 1970; Schaffer, 1974a,b; Schaffer and Gadgil, 1975; Bell, 1976; Schaeffer and Rosenzweig, 1977). When lifespan, competition, and reproduction are considered in an integrated context, the diversity of reproductive strategies becomes understandable, and general predictions are possible (see Jain, article 7; Cook, and Hickman).

Great strides in our understanding have also been made in the area loosely known as "physiological ecology," or "functional morphology." Although botanists have always tried to interpret form in terms of function, it is only in the last 20 years that this ideal has been translated into reality in populational studies. Advances in our understanding of basic phenomena such as the biochemistry of photosynthesis (Zelitch, 1969) and the mechanics of water and nutrient transport (Zimmermann, 1974), together with the development of reliable instrumentation for field use, have totally revolutionized this area. In Part 3 of this book, some of these advances, as 
well as the new and fascinating problems that have arisen from these approaches, are documented.

Studies of the genetic structure of populations need now to be integrated with demographic studies and with the more functional insights derived from physiological ecology. Since great lacunae exist in our knowledge of each of these three approaches, it may be premature to expect much integration at this time. However, as the papers in the three parts of this volume show, the genetic composition of the population is determined by the forces that structure the life history parameters through the morphological and physiological characteristics of the phenotype, which are in turn determined by the genotype and, ultimately, by the genetic structure of the population.

In choosing the topics for this book, the editors deliberately avoided the issues of the influence of community structure on population and species coevolution, and, in particular, plant-herbivore interactions. This was done in part because others are presently investigating these problems very competently (May, 1974; Gilbert and Raven, 1976) and in part because unless some boundaries, no matter how artificial, are set, we are in danger of becoming lost in a sea of data and general statements.

Because we do stand on the shoulders of our predecessors, it was felt important to present a review of the historical development of plant population biology (Stebbins, "Fifty Years of Plant Evolution"). Plant population biology as it is developing in the United States has three historical roots. First there is the "biosystematic" root, whose historical development is described by Stebbins. Starting with Turesson in the 1920s, the biosystematists documented the importance of breeding populations as the unit of evolution, the local nature of adaptation, and the genetic structure of species. A second historical root is the tradition of population ecology, which is concerned with the changes in numbers of indiviudals in populations. Although some classical work with plants was done in the 1920s (Clements et al., 1929), this approach was developed by animal ecologists and survived mostly among botanists in the applied fields (Harper, 1977). There has been a tremendous surge of interest in this area in the last 20 years, spurred largely by the drive 
and imagination of John Harper in Great Britain. Finally, the physiological-ecological approach also has a long tradition that reaches back to the German ecologist Andreas Fran Schimper and comes to us through Maximov and Walther. But it has only been in the last 20 years that plant physiology has been integrated into population studies, mainly as a result of a new and better understanding of the process of photosynthesis and the development of reliable field instrumentation. Although clearly defined conceptual approaches, techniques, and intellectual schools can be discerned within these three traditions, there has always been a fair amount of intellectual exchange between these areas, so that today's synthetic approach does not represent a radical departure.

The papers that follow represent an attempt by a generation of American plant population biologists in their 30s and 40 s to present their view of the field. Some papers are defenses of particular concepts (Horn, article 2); others represent critical evaluations of ideas and approaches (Jain and Hickman). Most papers synthesize the present status of theory and research on specific topics within plant population biology. Collectively, the book is our scientific manifesto, in which we indicate what we see as the present problems and future directions of this field.

The editors were solely responsible for choosing the general topics and assembling the participants. A conscious decision was made to favor members of the new generation. In so doing, we do not mean to denigrate in any way the great contribution of some of the more senior population biologists. Their work is the foundation of ours. Financial considerations excluded the participation of researchers from outside the United States. This we regret very much. Finally, not all invited persons could participate.

All contributors but one (M. Caldwell) attended a preliminary conference held at Ithaca College, in Ithaca, New York, on June 1618, 1977. The conference was attended also by a number of guests (see the list at the end of the book). We wish to thank all participants for their comments and contributions during the lively discussions that took place. We all benefited greatly. The papers were sent for review to the following persons, whose critical comments and editorial advice are acknowledged by editors and authors: P. Cavers, M. 
Clegg, B. Chabot, H. Lewis, R. Loomis, J. Mitten, R. Ornduff, H. Wilbur, and M. Zimmermann. Last but not least, we wish to thank the authorities of Ithaca College, especially S. LaMotte, and Brian Chabot of Cornell University, for local arrangements, and Kathryn W. Rollins and Anita Fahey of Harvard University for able editorial and secretarial assistance and organization help. Joe Ingram and Maria Caliandro of Columbia University were unfailing in their confidence in this project and their editorial advice. 